\section{Profil Efikasi Diri Peserta Didik Berdasarkan Hasil Belajar Biologi Kelas X MIA MAN 1 Makassar}

\author{
Sutarni \\ Hilda Karim \\ Muhiddin Pallennari
}

\begin{abstract}
Abstrak. Penelitian ini merupakan penelitian deskriptif yang bertujuan untuk mengetahui profil efikasi diri peserta didik berdasarkan hasil belajar biologi. Populasi dalam penelitian ini merupakan seluruh peserta didik kelas X MIA MAN 1 Makassar, sampel penelitian sebanyak 68 orang. Pengumpulan data dilaksanakan pada semester genap tahun ajaran 2017/2018. Data efikasi diri dikumpulkan menggunakan angket dan hasil belajar biologi diperoleh dari tes hasil belajar peserta didik. Data efikasi diri dan hasil belajar biologi dianalisis dengan statistik deskriptif. Hasil penelitian menunjukkan bahwa: (1) peserta didik dengan hasil belajar sangat tinggi, tinggi dan sedang tidak memiliki efikasi diri (2) peserta didik dengan hasil belajar rendah dan sangat rendah memiliki efikasi diri.

Kata kunci: penelitian deskriptif, efikasi diri, hasil belajar biologi.
\end{abstract}

\section{Pendahuluan}

Biologi adalah ilmu yang memperlajari segala sesuatu tentang makhluk hidup. Melalui biologi, manusia belajar mengenali dan memahami dirinya sendiri maupun makhluk hidup lainnya. Oleh karena itu, kita diharapkan tidak hanya pintar dalam hal akademik saja, namun dapat mengimplemenatasikan pengetahuan pada dunia nyata. Hal ini dapat terwujud apabila kita mampu menganalisis dan memahami suatu masalah yang membutuhkan pemahaman konsep dan keyakinan diri yang tinggi.

Pemahaman konsep merupakan dasar dari kemampuan dalam meyakinkan diri sendiri untuk menyelesaikan tugas-tugas yang diberikan. Kemampuan tersebut dinamakan self-efficacy (efikasi diri). selfefficacyadalah kepercayaan diri seseorang bahwa dia memiliki kemampuan untuk menyelesaikan tugas yang spesifik dengan sukses dan keyakinan ini berkaitan dengan kinerja dan ketekunan dalam berbagai usaha. Salah-satunya ialah usaha dalam mencapai prestasi belajar yang baik.

Guru yang merupakan salah satu komponen dari sekolah, memiliki andil yang besar dalam proses pendidikan. Guru harus memahami kebutuhan peserta didik selama proses pembelajaran, agar peserta didik dapat sukses mencapai tujuan pembelajaran, sebagai suatu totalitas dalam perannya sebagai seorang pembelajar. Guru yang merupakan salah satu komponen dari sekolah, memiliki andil yang besar dalam proses pendidikan. Guru harus memahami kebutuhan peserta didik selama proses pembelajaran, agar peserta didik dapat sukses mencapai

\section{Biology Teaching and Learning}

p-ISSN $2621-5527$
e-ISSN $2621-5535$

Abstract. This research is a descriptive research that aims to know the selfefficacy profile of students based on biology learning result. The population in this study is all students of class X MIA MAN 1 Makassar, sample of research is 68 people. Data collection was conducted in even semester of academic year

2017/2018. Data of self-efficacy obtained by questionnaire and biology learning result obtained from biology learning result test. Data of self-efficacy and biology learning result analyzed by using descriptive statistics. The results showed that: (1) for students with very high, high and medium of biology learning result have not self-efficacy (2) for students with low and very low of biology learning result have self-efficacy.

Keywords: descriptive research, selfefficacy, biology learning result.

Sutarni

Universitas Negeri Makassar Indonesia

Hilda Karim

Universitas Negeri Makassar Indonesia

Muhiddin, Pallenari Universitas Negeri Makassar Indonesia 
tujuan pembelajaran, sebagai suatu totalitas dalam perannya sebagai seorang pembelajar. Hasil belajar merupakan tolak ukur keberhasilan kegiatan pembelajaran. Salah satu faktor penting yang menentukan keberhasilan peserta didik dalam belajar adalahkeyakinan diri. Mereka yang mampu meyakinkan dirinya dalam menyelesaikan tugas kemungkinan memiliki peluang berhasil yang besar dalam belajar, dan sebaliknya mereka yang tidak memiliki keyakinan menghadapi apalagi untuk menyelesaikan tugasmemiliki kemungkinan yang kecil untuk berhasil dalam belajar.

Hasil penelitian Nirwana (2015) yang dilakukan di sekolah dasar daerah binaan iv kecamatan cilacap selatan kabupaten cilacap bahwa terdapat pengaruh efikasi diri terhadap hasil belajar peserta didik dengan persetanse sebesar $29,6 \%$ sedangkan 70,4\% dipengaruhi oleh faktor lain yang tidak dibahas dalam penelitian. Hasil penelitian di atas juga sejalan dengan penelitian Sofwan (2015),didapatkan nilai korelasi sebesar 0,353 yang berarti terdapat korelasi antara selfefficacy terhadap hasil belajar.

Berdasarkan hasil observasi awal peneliti di MAN 1 Makassar yang merupakan lokasi penelitian, peneliti melihat bahwa kebanyakan peserta didik tidak percaya diri selama pembelajaran berlangsung. dikarenakan peserta didik merasa bosan dengan kegiatan pembelajaran yang tidak sesuai dengan apa yang mereka butuhkan, sehingga pada tugas yang lebih spesifik tidak dapat diselesaikan.

\section{Rumusan Masalah}

Rumusan masalah dalam penelitian ini sebagai berikut, bagaimana profil (gambaran) efikasi diri peserta didik berdasarkan hasil belajar biologi peserta didik kelas X MIA MAN 1 Makassar.

\section{Metode Penelitian}

\section{Latar Belakang Umum Penelitian}

Penelitian ini merupakan penelitian deskriptif yang bertujuan untuk mengetahui profil efikasi diri peserta didik berdasarkan hasil belajar biologi kelas X MIA MAN 1 Makassar. Variabel dalam penelitian ini terdiri dari dua variabel yaituefikasi diri (X) sebagai variabel bebas, dan hasil belajar (Y) sebagai variabel terikat. Penelitian ini menggunakan desain penelitian deskriptif korelasional dengan keterkaitan antar variabel digambarkan sebagai berikut.

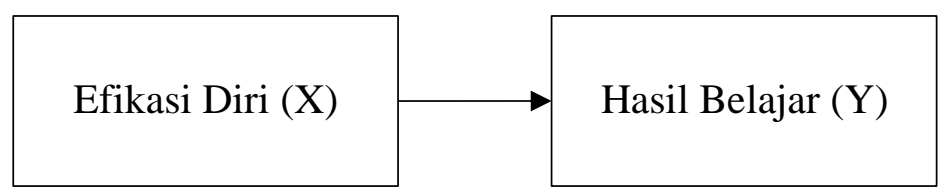

Gambar 1. Desain Penelitian X dan Y

Definisi operasional variable, efikasi diri merupakan suatu sikap menilai atau mempertimbangkan kemampuan diri sendiri dalam menyelesaikan tugas yang spesifik. Kemampuan ini diukur dengan menggunakan lima indikator yang tertuang dalam angket yaitu; (1) keyakinan terhadap kemampuan diri, (2) keyakinan terhadap kemampuan menyelesaikan dan menghadapi tugas-tugas, (3) keyakinan terhadap kemampuan menghadapi tantangan, (4) keyakinan terhadap menyelesaikan tugas yang spesifik, dan (5) keyakinan terhadap kemampuan menyelesaikan beberapa tugas yang berbeda. Kelima indikator tertuang dalam tiga dimensi dari self-efficacy itu sendiri; dimensi magnitude, dimensi strength, dan dimensi generality. Dimensi magnitude berhubungan dengan tingkat kesulitan yang diyakini oleh individu untuk dapat diselesaikan, dimensi strength berhubungan dengan tingkat kekuatan atau kelemahan keyakinan individu tentang kompetensi yang dipersepsinya, dan dimensi generality menunjukkan apakah 
keyakinan diri akan berlangsung dalam domain tertentu atau berlaku dalam berbagai macam aktivitas dan situasi. Hasil belajar peserta didik dalam penelitian merupakan rata-rata dari nilai tes hasil belajar biologikelas X MIA MAN 1 Makassar.

\section{Sampel Penelitian}

Teknik yang digunakan dalam penelitian ini adalah simple random sampling. Simple random samplingadalah teknik penentuan sampel dengan cara pengambilan secara acak (Sugiyono, 2016). Sampel dalam penelitian ini diambil menggunakan buku paket biologi yang sama dan pembagian kelas tidak ada kelas unggulan. Sampel dalam penelitian ini merupakan peserta didik kelas X MIA 3 dan X MIA 4 yang berjumlah 68 orang.

\section{Instrumen dan Prosedur Penelitian}

Penelitian ini menggunakan dua jenis instrumen yaitu instrument non-tes berupa angket self-efficacy peserta didik yang diadaptasi dan dikembangkan dari Achmad (2013). Dan instrumen tes berupa tes tertulis yaitu tes hasil belajar sebanyak 30 nomor soal pilihan ganda. Peneliti menggunakan angket dengan skala Likert untuk mendapatkan jawaban yang tegas (konsisten) terhadap suatu permasalahan yang ditanyakan. Angket berisi 18 pernyataan yang mencakup ke 5 indikator self-efficacy. Tes hasil belajar disusun berdasarkan indikator yang ingin dicapai dalam pembelajaran. Prosedur penelitian terdiri dari tiga tahap yaitu: (1) tahap persiapan, (2) tahap pelaksanaan, dan (3) tahap akhir.

\section{Analisis Data}

\section{Analisis Statistik Deskriptif}

Analisis statistik deskriptif dalam penelitian ini digunakan untuk mendeskripsikan hasil belajar biologi dan self-efficacy yang dimiliki peserta didik. Skor self-efficacy diperoleh dengan cara menjumlahkan nilai dari semua item/ pernyataan.

Adapun rumus untuk mendapatkan nilai hasil belajar sebagai berikut.

Keterangan:

$$
N=\frac{\sum X}{\sum Y} \times 100
$$

$$
\begin{array}{ll}
N & =\text { nilai hasil belajar } \\
\sum X & =\text { skor yang diperoleh } \\
\sum Y & =\text { skor maksimal }
\end{array}
$$

\section{Analisis Statistik Inferensial}

Analisis statistik inferensial digunakan peneliti untuk menganalisis data hasil angket selfefficacy dengan menggunakan uji korelasi sederhana. Teknik analisis korelasi sederhana digunakan untuk mengetahui hubungan antar variabel.

\section{Uji Hipotesis}

Uji hipotesis yang digunakan dalam penelitian ini adalah uji Korelasi Product Moment. Uji hipotesis dilakukan untuk mencari hubungan variabel bebas terhadap variabel terikat yang dianalisis pada taraf signifikansi $95 \%(\alpha=0,05)$. Adapun rumusan hipotesis yang akan diuji dalam penelitian ini adalah sebagai berikut. 
1. $H_{0}: \rho_{x y}=0$, tidak ada hubungan antara self-efficacy dengan hasil belajar biologi peserta didik kelas X MIA MAN 1 Makassar.

2. $H_{1}: \rho_{x y} \neq 0$, ada hubungan antara self-efficacy dengan hasil belajar biologi peserta didik kelas X MIA MAN 1 Makassar.

\section{Hasil Penelitian}

\section{Deskripsi Self-efficacy Peserta Didik}

Data Self-efficacy peserta didik kelas X MIA MAN 1 Makassar diketahui dengan mengkategorikan keseluruhan nilai rata-rata yang dimiliki oleh peserta didik. Self-efficacy peserta didik diolah menggunakan aplikasi SPSS 22.

Self-efficacy peserta didik dikelompokkan dalam 5 kategori yaitu; sangat tinggi, tinggi, sedang, rendah dan sangat rendah. Distribusi frekuensi dan persentase self-efficacy peserta didik kelas X MIA MAN 1 Makassar dapat dilihat pada tabel berikut.

Tabel 1. Frekuensi dan Persentase Self-efficacy Peserta Didik

\begin{tabular}{|c|c|c|}
\hline Kategori Self-efficacy & Frekuensi (F) & Persentase (\%) \\
\hline Sangat Tinggi & 0 & 0 \\
\hline Tinggi & 19 & 27,94 \\
\hline Sedang & 37 & 54,41 \\
\hline Rendah & 11 & 16,18 \\
\hline Sangat Rendah & 1 & 1,47 \\
\hline Jumlah & $\mathbf{6 8}$ & $\mathbf{1 0 0}$ \\
\hline
\end{tabular}

Self-efficacy peserta didik terdiri atas 3 dimensi yaitu; dimensi magnitude (meliputi indicator 1 dan 2), dimensi strength (memuat indicator 3), dan dimensi generality (memuat indikator 4 dan 5). Distribusi frekuensi dan persentase self-efficacy peserta didik berdasarkan dimensinya dapat dilihat pada tabel berikut.

Tabel 2. Persentase Dimensi Self-efficacy Peserta Didik

\begin{tabular}{|c|c|c|c|}
\hline Kategori & Dimensi Magnitude & Dimensi Strength & $\begin{array}{c}\text { Dimensi } \\
\text { Generality }\end{array}$ \\
\hline Sangat Tinggi & $0 \%$ & $0 \%$ & $0 \%$ \\
\hline Tinggi & $0 \%$ & $0 \%$ & $0 \%$ \\
\hline Sedang & $0 \%$ & $0 \%$ & $0 \%$ \\
\hline Rendah & $95.59 \%$ & $86.77 \%$ & $92.65 \%$ \\
\hline Sangat Rendah & $4.41 \%$ & $13.23 \%$ & $7.35 \%$ \\
\hline Jumlah & $\mathbf{1 0 0} \%$ & $\mathbf{1 0 0} \%$ & $\mathbf{1 0 0} \%$ \\
\hline
\end{tabular}

\section{Deskripsi Hasil Belajar Biologi Peserta Didik}

Data hasil belajar peserta didik kelas X MIA MAN 1 Makassar diketahui dengan mengkategorikan keseluruhan nilai rata-rata yang dimiliki oleh peserta didik. Hasil belajar peserta didik diolah menggunakan aplikasi SPSS 22. Nilai hasil belajar peserta didik dikategorikan menjadi 5 kategori yang dibuat berdasarkan nilai rata-rata (mean) 73.82 dan Kriteria Ketuntasan Minimal (KKM) yang ditentukan yaitu 70. Profil self-efficacy peserta didik berdasarkan hasil belajar biologi yang dilihat dari dimensi self-efficacy peserta didik, ditunjukkan pada tabel berikut: 
Tabel 3. Profil Self-efficacy Berdasarkan Hasil Belajar Biologi Peserta Didik

\begin{tabular}{|c|c|c|c|}
\hline \multirow{2}{*}{ Hasil Belajar } & \multicolumn{3}{|c|}{ Dimensi Self-efficacy } \\
\cline { 2 - 4 } & Magnitude & Strength & Generality \\
\hline Sangat Tinggi & 0 & 0 & 0 \\
\hline Tinggi & 0 & 0 & 0 \\
\hline Sedang & 0 & 0 & 63 \\
\hline Rendah & 65 & 59 & 5 \\
\hline Sangat Rendah & 3 & 9 & $\mathbf{6 8}$ \\
\hline Jumlah & $\mathbf{6 8}$ & $\mathbf{6 8}$ & \\
\hline
\end{tabular}

\section{Pembahasan}

Sebagian besar efikasi diri peserta didik berada pada kategori sedang dengan frekuensi sebanyak 37 orang (54.41\%), diikuti efikasi diri berkategori tinggi dengan frekuensi 19 orang (27.94\%), kemudian efikasi diri dengan kategori rendah sebanyak 11 orang (16.18\%). Jika dilihat dari ketiga dimensi efikasi itu sendiri, peserta didik memiliki efikasi diri yang tergolong rendah dan sangat rendah. Efikasi diri peserta didik yang dominan yaitu pada kategori sedang dipengaruhi oleh beberapa hal, salah satunya adalah hasil belajar peserta didik. Hal tersebut menuntut peserta didik untuk dapat meyakinkan diri agar mampu menyelesaikan permasalahan yang dihadapinya.

Kategori hasil belajar yang dominan dari 68 peserta didik adalah kategori sedang yaitu sebanyak 46 orang $(67,65 \%)$. Tetapi juga didapatkan peserta didik dengan hasil belajar pada kategori sangat tinggi sebanyak 1 orang $(1,47 \%)$ dan pada kategori tinggi sebanyak 13 orang $(19,12 \%)$. Meskipun pada dimensi efikasi diri menunjukkan bahwa 68 peserta didik berada pada kategori rendah dan sangat rendah, tetapi untuk kedua kategori tersebut pada hasil belajar peserta didik hanya terdapat 8 orang saja. Hal ini dapat membuktikan efikasi diri peserta didik tidak hanya dipengaruhi oleh hasil belajar.

Berdasarkan dimensi self-effycacy peserta didik: 1) pada dimensi magnitude, terdapat 95.59\% peserta didik yang memiliki efikasi diri yang rendah dan $1.47 \%$ peserta didik yang memiliki efikasi sangat rendah, 2) pada dimensi strength, terdapat $86.77 \%$ peserta didik yang memiliki efikasi diri rendah dan $12.23 \%$ peserta didik yang memiliki efikasi diri sangat rendah, dan 3) pada dimensi generality, terdapat $92.65 \%$ peserta didik dengan efikasi yang rendah dan 7.33\% peserta didik dengan efikasi diri sangat rendah. Hal ini menunjukkan bahwa, peserta didik dengan hasil belajar tinggi, tidak memiliki efikasi diri sedangkan peserta didik yang memiliki efikasi diri ialah peserta didik dengan hasil belajar rendah dan sangat rendah. Hal ini karena efikasi diri individu memiliki banyak faktor yang dapat mempengaruhinya, yaitu pengalaman keberhasilan, pengalaman orang lain, persuasi sosial, dan keadaan fisiologis dan emosional. Artinya, hasil belajar (pengalaman keberhasilan) hanya salah satu faktor dari banyak faktror yang dapat mempengaruhi self-efficacy.

\section{Kesimpulan}

Berdasarkan analisis data dalam hasil penelitian, kesimpulan: Pertama, peserta didik dengan hasil belajar sangat tinggi, tinggi dan sedang tidak memiliki efikasi diri. Kedua, peserta didik dengan hasil belajar biologi rendah dan sangat rendah memiliki efikasi diri

\section{Referensi}

Adiputra, S. (2015). Keterkaitan Self-efficacy dan Self-esteem terhadap Prestasi Belajar Mahasiswa. Jurnal Fokus Konseling, 1 (2). 
Pertiwi, N. Pengaruh Self-efficacy terhadap Hasil Belajar pada Siswa Kels V Sekolah Dasar Daerah Binaan IV Kecamatan Cilacap Selatan Kabupaten Cilacap. Skripsi. Diterbitkan. Semarang. Universitas Negeri Semarang.

Pujiyanto, S. \& Ferniah R. S. (2016). Menjelajahi Dunia Biologi. Semanrang. Tiga serangkai.

Purnamasari, M. I. (2014). Hubungan Self- Efficacy dan Motivasi Berprestasi dengan Kecmasan Mahasiswa yang Sedang Mngerjakan Skripsi. Skripsi. Surakarta. Univeristas Negeri Surakarta.

Widiyanto, A. (2013). Pengaruh Self-efficacy dan Hasil Belajar Siswa Terhadap Kemandirian Mata Pelajaran Keselamatan Kerja di SMKN 2 DEPOK. Skripsi. Yokyakarta. Universitas Negeri Yokyakarta.

\begin{tabular}{|l|l|}
\hline Sutarni & $\begin{array}{l}\text { Jurusan Biologi, Fakultas Matematika dan Ilmu Pengetahuan Alam, } \\
\text { Universitas Negeri Makassar. } \\
\text { Email: } \text { sutarnibiologi@gmail.com }\end{array}$ \\
\hline Hilda Karim & $\begin{array}{l}\text { Dr. M.S Dosen Jurusan Biologi, Fakultas Matematika dan Ilmu } \\
\text { Pengetahuan Alam, Universitas Negeri Makassar. } \\
\text { Email: hildakarim@yahoo.com }\end{array}$ \\
\hline Muhiddin Pallenari & $\begin{array}{l}\text { Dr. M.Pd Dosen Jurusan Biologi, Fakultas Matematika dan Ilmu } \\
\text { Pengetahuan Alam, Universitas Negeri Makassar. } \\
\text { Email: } \underline{\text { muhiddin-69@unm.ac.id }}\end{array}$ \\
\hline
\end{tabular}

